\title{
Quantum Mechanical Modeling Unveil the Effect of Substitutions on the Activation Barriers of the Diels- Alder Reactions of an Antiviral Compound 7H- Benzo[a]phenalene
}

\author{
Umatur Rehman
}

Government College University Faisalabad

Asim Mansha ( $\square$ mansha.asim@gmail.com )

Government College University Faisalabad https://orcid.org/0000-0001-5659-0562

Muhammad Zahid

Government College University Faisalabad

\section{Sadia Asim}

Government College Women University Faisalabad

\section{Ameer Fawad Zahoor}

Government College University Faisalabad

\section{Zulfiqar Ahmad Rehan}

National Textile University

\section{Research Article}

Keywords: Computational exploration, Reaction mechanism, Substituent effect, Energy barrier, $7 \mathrm{H}-$ benzo[a]phenalene, transition states

Posted Date: December 14th, 2021

DOI: https://doi.org/10.21203/rs.3.rs-1134308/v1

License: (9) This work is licensed under a Creative Commons Attribution 4.0 International License. Read Full License 


\section{Abstract}

Density functional theory has been utilized for exploring the mechanism of Diels-Alder reaction between $7 H$-benzo[a]phenalene and maleic anhydride. $7 H$-Benzo[a]phenalene is an antiviral compound and information available about its cycloaddition reactions with possible reaction path and mechanism is scarce. In order to work on the synthesis of its further potential derivatives, the mechanism of its reaction with all aspects should be well understood. Two novel intermediates involved in this reaction have been reported. Diels-Alder reaction of maleic anhydride has found many applications in the synthesis of wide range of useful products. The major concern of this work is to evaluate the consequences of introducing electron donating and electron withdrawing substituents on the reactivity of maleic anhydride towards $7 H$-benzo[a]phenalene. Thermodynamic parameters, activation parameters, energies of frontier orbitals, global reactivity indices and global electron density transfer (GEDT) have been determined for all the reactions. Fukui functions are computed for each reactant in order to identify the most reactive sites. All the reactions have been found to proceed via normal electron demand having polar nature. The substituents with opposite electronic properties were expected to affect the reactivity of dienophile in an inverse manner, however, the results are not according to this assumption. Rather, both kinds of substituents increased the activation barrier of the reaction. This behavior has been explained in the light of various parameters such as the stability of reacting species, gap of frontier molecular orbitals etc. Experimental studies reported previously are in agreement with these results.

\section{Introduction}

Diels-Alder (DA) reaction is a dominant strategy for the production of synthetically important molecules $[1,2]$ and involves two reactants i.e. a diene and a dienophile [3] which react with each other through a concerted mechanism following [4+2] cycloaddition. DA reaction, developed in 1928 by Otto Diels and Kurt Alder [4], results in the formation of six membered ring with two new sigma bonds and a well-defined stereochemistry [5]. It is one of the most reliable and economical methods for the formation of carboncarbon bond in organic chemistry [6]. For several years, it has gained attention of experimental as well as theoretical chemists [7]. The significance of Diels-Alder reaction has not decreased since several decades. Even today, this reaction finds same importance as it gained about fifty years ago [8]. One of its major applications involves the synthesis of biologically active natural products [9-12]. DA reaction has been proposed as a unique pathway for synthesizing $\mathrm{C}_{60}[13]$ and surface modification of carbon materials [14]. Hetero-DA reactions are important for the synthesis of heterocyclic compounds $[15,16]$ which are well known for their pharmaceutical applications [17]. Hetero-DA reactions involving conjugated nitroalkenes are widely used for preparing six-membered internal nitronates [18]. Maleic anhydride, a heterocyclic dienophile, takes part in a wide range of cycloaddition reactions [19]. The presence of highly polarized $\mathrm{C}=\mathrm{O}$ bond is responsible for making it a suitable dienophile [20]. It can be produced at industrial scale by the oxidation of $n$-butane and benzene [21]. Modification of substituents or groups in diene or dienophile can alter the regioselectivity [22] and rate of reaction to large extent [23, 24] e.g., very high reactivity of (carbomethoxy)maleic anhydride in DA reaction is due to the presence of carbomethoxy 
group on maleic anhydride [19]. Generally, electron withdrawing substituents on dienophile and electron donating groups on diene increase the rate of the reaction [25]. The extent to which they alter reaction rate is dependent on the second reacting species as well e.g., methyl substituent on diene showed different effect on the reaction barrier with two different dienophiles [26]. Silicon and boron substituted dienes and dienophiles have been studied heavily due to their ease of handling and synthesis [27]. Good understanding of reaction mechanisms is crucial in improving the rout for the synthesis of industrially, medicinally and agriculturally useful products $[28,29]$. Computational chemistry provides important information about reaction mechanisms that could not be obtained previously by experimental methods [30-32].

In present article, complete reaction mechanism of maleic anhydride with $7 H$-benzo[a]phenalene has been studied with density functional theory. $7 \mathrm{H}$-benzo[a]phenalene is an organic compound which has potential of being used as an antiviral drug [33] and mechanism of its reactions with different anhydrides must be helpful for the determination of its important properties regarding reactivity and for economical synthesis of its derivatives. Density functional theory is selected because it has been proved to be a very good choice for the study of Diels-Alder reaction [34]. The nature of reaction has been determined by the analysis of global electron density transfer at transition state, analysis of global reactivity descriptors [35], molecular electrostatic potential etc. Fukui functions for the reacting molecules are calculated to predict their most reactive sites [36]. Thermodynamic parameters and activation parameters for all the steps of reaction are computed. The effect of electron donating and electron withdrawing substituents on activation barriers and energies of highest occupied orbitals and lowest occupied orbitals have been analyzed. Reactions of maleic anhydride with furans [37], anthracenes [38, 39] and many other compounds have been very frequently studied experimentally and computationally but information available on reactions of $7 H$-benzo[a]phenalene (produced by the distillation of benzanthrone with zinc dust [40]) is very little. In fact, even a single report on computational study of its reaction could not be traced.

\section{Computattional Methdologies}

According to Mats Linder and Tore Brinck, M06-2X is a good choice for optimizing transition states of Diels-Alder reaction [41]. Therefore, all the structures were optimized with M06-2X functional and 6$311++G(d, p)$ basis set in gas phase [42]. M06-2X functional was developed by Zhao and Truhlar and it was parameterized for better description of transition states [43]. Transition states were optimized by using berny algorithm [44]. Frequency calculation were also performed at the same level of theory for calculating thermodynamic parameters and for ensuring nature of stationary points [45]. All the reactants, products and intermediates have no imaginary frequency while all transition states have only one imaginary frequency [46]. For performing all the calculations Gaussian 09W was employed [47, 48]. GaussView 6.0.16 was utilized as graphical user interface. Activation thermodynamic parameters and activation barriers were computed at $298.15 \mathrm{~K}$ and $1 \mathrm{~atm}$. Thermodynamic properties like enthalpy, entropy and free energies for each structure were obtained at same conditions. Energies for $\mathrm{HOMO}$ and 
LUMO ( $E_{\text {HOMO }}$ and $\left.E_{\text {LUMO }}\right)$ for each structure involved in the reactions were calculated. Furthermore, chemical hardness $(\eta)$ and chemical softness $(S)$ from energies of frontier molecular orbitals were calculated by using the following equations [45]:

$$
=\frac{E_{\mathrm{LUMO}}-\mathrm{E}_{\mathrm{HOMO}}}{2}
$$

1

\&amp;\#x03B7;

$$
S=\frac{1}{\eta}
$$

2

From the values of hardness/softness, global electrophilicity index $(\omega)$ was determined by using simple relation given bellow [49]:

$$
=\frac{\mu^{2}}{2 \eta}
$$

3

\&amp;\#x03C9;

Where $\mu$ is electronic chemical potential computed by using following expression [50]:

$\mu=\frac{\mathrm{E}_{\mathrm{LUMO}}+\mathrm{E}_{\mathrm{HOMO}}}{2}(4)$

Following relation is used for the calculation of nucleophilicity index $(\mathrm{N})$ [51].

$\mathrm{N}=\mathrm{E}_{\mathrm{HOMO}}$ (Nucleophile) $-\mathrm{E}_{\mathrm{HOMO}(\mathrm{TCE})}(5)$

TCE is tetracyanoethylene which is selected as reference in nucleophilicity scale due to its lowest HOMO energy [52]. Structure of TCE was optimized at M06-2x/6-311++G(d,p) level in order to compute $N$ for all molecules.

Fukui functions were calculated according to following relations:

$f+\approx q_{k}(N+1)-q_{k}(N)$ (For attack of nucleophile) (6)

$\mathrm{f}-\approx \mathrm{q}_{\mathrm{k}}(\mathrm{N})-\mathrm{q}_{\mathrm{k}}(\mathrm{N}-1)$ (For attack of electrophile) (7)

In this equation $\mathrm{q}_{k}(\mathrm{~N}) \mathrm{qk}(\mathrm{N}+1)$ and $\mathrm{q}_{\mathrm{k}}(\mathrm{N}-1)$ are populations of atom $\mathrm{k}$ in a system having $\mathrm{N}, \mathrm{N}+1$ and $\mathrm{N}-1$ electrons respectively. Whereas, $\mathrm{f}+$ and $\mathrm{f}$ - describes the reactivity when electrons are added to system and removed from system respectively [53]. 


\section{Results And Discussions}

In the first step of reaction A (scheme 1), 7 H-benzo[a]phenalene (1a) and maleic anhydride (2a) come close to form transition state (TS1a). Dipole moment of TS1a is 5.4 Debye which is higher than the dipole moments of the reacting species i.e., 4.4 Debye for maleic anhydride (2a) and 0.44 Debye for $7 \mathrm{H}-$ benzo[a]phenalene (1a). TS1a leads to the formation of an unstable intermediate $3 a$ [40] which has a dipole moment of 5.3 Debye. In the 2nd step, $\mathrm{H} 28$ is transferred from $\mathrm{C} 12$ to $\mathrm{C} 17$ resulting in formation of 2nd intermediate (4a). 3rd step involves the transfer of H32 from C20 to C23 and this step needs an activation energy of $36.34 \mathrm{kcal} / \mathrm{mol}$ to form $3 \mathrm{rd}$ intermediate (5a). Although $5 \mathrm{a}$ is more stable than reactants yet it gets converted to an even more stable final product (6a) which has a dipole moment of 5.7 Debye. During transformation of $5 \mathrm{a}$ to $6 \mathrm{a}, \mathrm{H} 30$ moves from C18 to C21. Dihedral angle of C3, C1, C2 and $\mathrm{C} 5$ is $0^{\circ}$ in reacting species while, its value in $3 \mathrm{a}$ is $-33.7^{\circ}$ which further changes to $-23.9^{\circ}$ in $6 \mathrm{a}$. Bond length of $\mathrm{C} 1-\mathrm{C} 2$ in $2 \mathrm{a}$ is $1.3 \AA$ which increases to $1.5 \AA$ in $6 \mathrm{a}$. Energy of all the structures relative to reactants is given in Fig. 1. In Fig. 2, structures of reactants i.e., $1 \mathrm{a}$ and $2 \mathrm{a}$ are shown along with labelling and numbering of atoms.

Table 1 elaborates the thermodynamic activation parameters and activation energy for different steps of reaction mentioned in scheme 1 . The conversion of 3a into 4a via TS2a shows highest activation energy, therefore, it is the slowest step i.e. rate determining step for the reaction [54]. Free energy of activation is also maximum for this conversion. Activation energy for the first step is minimum. Thus, the formation of 3a is faster as compared to formation of any other intermediate involved in reaction. It is to be noted that activation energy and enthalpy of activation follow same trend. They decrease in following order:

step 2 > step 3 > step 4 > step 1

Table 1

Values of thermodynamic activation parameters for each step of scheme 1 at M06-2X/6-311++G(d,p)

\begin{tabular}{|lllll|}
\hline $\begin{array}{l}\text { Step } \\
\text { Number }\end{array}$ & $\begin{array}{l}\text { Activation } \\
\text { energy(kcal/mol) }\end{array}$ & $\begin{array}{l}\text { Free energy of } \\
\text { activation(kcal/mol) }\end{array}$ & $\begin{array}{l}\text { Enthalpy of } \\
\text { activation(kcal/mol) }\end{array}$ & $\begin{array}{l}\text { Entropy of } \\
\text { activation(Cal/mol/K) }\end{array}$ \\
\hline 1 & 9.3 & 26.73 & 11.12 & -52.34 \\
\hline 2 & 75.9 & 72.14 & 71.92 & -0.74 \\
\hline 4 & 36.3 & 33.74 & 33.09 & -2.16 \\
\hline
\end{tabular}

The trend in free energy of activation differs from these two parameters (activation energy and enthalpy). Sequence of decrease in its value is step $2>$ step $3>$ step $1>$ step 4

Negative values of activation entropy indicate that all the transition states have less degree of freedom as compared to the corresponding reacting species [55]. 
Thermodynamic properties have been used for predicting the spontaneity of chemical reactions and stability of product obtained [56]. Enthalpies, entropies and free energies (relative to reactants) of all structures involved in the scheme 1 are given in Table 2 . Enthalpy of final product (6a) is $-40.2 \mathrm{kcal} / \mathrm{mol}$ which indicates that the overall reaction proceeds exothermally. Apart from $6 \mathrm{a}$ and $5 \mathrm{a}$, each structure has higher value of enthalpy compared to reactants. The first step of reaction, in which cycloaddition occurs, is endothermic and endergonic [57] step as the calculated values of $\Delta \mathrm{H}$ and $\Delta \mathrm{G}$ are $11.2 \mathrm{kcal} / \mathrm{mol}$ and $25.7 \mathrm{kcal} / \mathrm{mol}$, respectively. This indicates that this step cannot occur spontaneously at the specified conditions of $298.15 \mathrm{~K}$ and $1 \mathrm{~atm}$.

Values of these parameters for 2nd step are $17.7 \mathrm{kcal} / \mathrm{mol}$ and $17.46 / \mathrm{kcal} / \mathrm{mol}$, thus this step is also endothermic and endergonic. The calculations of these values for 3rd and 4th steps revealed that these steps were exothermic and exergonic. $\Delta \mathrm{H}$ for these steps is $-39.72 \mathrm{kcal} / \mathrm{mol}$ and $-29.46 \mathrm{kcal} / \mathrm{mol}$ while $\Delta \mathrm{G}$ for them is $-38.9 \mathrm{kcal} / \mathrm{mol}$ and $-29.89 \mathrm{kcal} / \mathrm{mol}$ respectively.

The overall entropy change in this reaction is negative, it is obvious because here two molecules are combining to form a single adduct. Decrease in entropy during formation of TS1a from two separate reactants is significantly large. Formation of other transition states also accompany negative entropy change, but the values of this change are much smaller as compared to the TS1a. This finding is consistent with the fact that TS1a is formed from two different molecules which are not covalently bonded to each other. Thus, their degree of freedom is greatly reduced which causes entropy to decrease by such a huge value [58]. Decrease in entropy is a factor that does not favors the proceeding of reaction [52].

Table 2

Values of thermodynamic parameters for scheme 1 are reported relevant to reactants at M06-2X/6-311++G(d,p)

\begin{tabular}{|llll|}
\hline Structure & $\begin{array}{l}\Delta H \\
(\mathrm{kcal} / \mathrm{mol})\end{array}$ & $\begin{array}{l}\Delta S \\
\left(\mathrm{Calmol}^{-1} \mathrm{~K}^{-1}\right)\end{array}$ & $\begin{array}{l}\Delta G \\
(\mathrm{kcal} / \mathrm{mol})\end{array}$ \\
\hline 3a & 11.2 & -48.62 & 25.7 \\
\hline TS2a & 83.2 & -49.357 & 97.9 \\
\hline 4a & 28.9 & -47.683 & 43.2 \\
\hline TS3a & 62.1 & -49.844 & 76.9 \\
\hline 5a & -10.7 & -50.287 & 4.3 \\
\hline TS4a & 11.1 & -52.003 & 26.6 \\
\hline 6a & -40.2 & -48.864 & -25.6 \\
\hline
\end{tabular}

All the factors mentioned in Table 1 and 2 were computed at B3LYP/6311++G(d,p) level as well. The comparison of the results of B3LYP and M06-2X functional revealed a variation among the results of 
these two functionals, particularly, the factors associated with 1st step (cycloaddition) showed most significant variations. According to Max Linder and Tore Brinck, M06-2X is a better choice for studying Diels Alder reaction and due to this reason, the results of only this functional have been discussed in detail [41]. Entropy is the parameter which is least affected by the change of functional.

Examining the transfer of electron density during the course of a chemical reaction, provides useful information that helps in understanding and controlling the chemical reactions [59]. To illustrate the process of electron density transfer in better way, molecular electrostatic maps (MESP) for all structures (Fig. 3) were computed. For this purpose, electrostatic potential was mapped on the self-consistent field (SCF) of total electron density [60]. MESP can be calculated directly from electron density and structural information could be obtained easily from standard quantum chemical calculations [61]. These maps display the distribution of electron density on molecules; different colors depict different values of electron density. Red color indicates the high electron density while blue color shows electron deficient site $[55,62]$. MESP has been utilized for understanding many important problems in chemistry e.g. for studying site of attack by electrophile/nucleophile in a molecule and its reactivity [63]. In the 1st step of scheme 1, C20 and C18 in 1a approaches C1 and C2 of 2a. In MESP of 1a and 2a, it can be seen that C20 and $\mathrm{C} 18$ are electron rich sites while $\mathrm{C} 1$ and $\mathrm{C} 2$ are regions of low electron density in maleic anhydride. Thus, it is expected from their MESP that $1 \mathrm{a}$ is acting as nucleophile and $2 \mathrm{a}$ is acting as an electrophile in this reaction. This result is later confirmed by the frontier orbitals analysis of reactants which shows that reaction between $1 \mathrm{a}$ and $2 \mathrm{a}$ is normal electron demand.

Table 3

$\mathrm{E}_{\mathrm{LUMO}}, \mathrm{E}_{\mathrm{HOMO}}$ and $\mathrm{E}_{\mathrm{LUMO}}$-HOMO for all species involved in scheme 1 at M06-2X/6-311++G(d,p)

\begin{tabular}{|llll|}
\hline Stationary point & $E_{\text {LUMO }}(e V)$ & $E_{\text {HOMO }}(e V)$ & $E_{\text {LUMO-Hомо }}(e V)$ \\
\hline $2 a$ & -2.36 & -10.48 & 8.12 \\
\hline 1a & -0.84 & -6.85 & 6.02 \\
\hline TS1a & -1.48 & -6.73 & 5.25 \\
\hline 3a & -1.44 & -6.83 & 5.38 \\
\hline TS2a & -1.99 & -5.28 & 3.29 \\
\hline 4a & -2.15 & -6.03 & 3.88 \\
\hline TS3a & -1.75 & -5.30 & 3.55 \\
\hline 5a & -0.99 & -7.22 & 6.23 \\
\hline TS4a & -1.39 & -6.82 & 5.42 \\
\hline 6a & -0.85 & -7.36 & 6.51 \\
\hline
\end{tabular}


Analysis of frontier orbitals (HOMO and LUMO) provides useful information about the reactivity of the molecules [64]. It is possible to determine electron donating ability and electron accepting abilities of molecules from $\mathrm{E}_{\mathrm{HOMO}}$ and $\mathrm{E}_{\mathrm{LUMO}}$ respectively [65]. Therefore, the energies of these orbitals are calculated for all the structures involved in the scheme 1 (Table 3). Difference in energies of LUMO and HOMO throws light on kinetic stability of the molecules. Higher value of $\mathrm{E}_{\mathrm{LUMO}-\mathrm{HOMO}}$ indicates that structure has greater kinetic stability and it is not very reactive, whereas, lower gap in energies of frontier orbitals reveals lower stability and highly reactive nature of the molecule [64]. It is evident from Table 3 that all the transition states have relatively lower values of $\mathrm{E}_{\mathrm{LUMO}-\mathrm{HOMO}}$ as compared to the corresponding reactants and products which is consistent with highly reactive nature of transition states [66].

By using the values of energies for frontier orbitals of diene ( $7 \mathrm{H}$-benzo[a]phenalene) and dienophile (maleic anhydride), it can be observed whether the reaction is normal electron demand or inverse electron demand [67]. For this purpose, gap of HOMO of dienophile and LUMO of diene was calculated (Fig. 4), which is found to be $9.6 \mathrm{eV}$. While gap between LUMO of dienophile and HOMO of diene is $4.5 \mathrm{eV}$. As the difference of $\mathrm{HOMO}_{\text {diene }}$ and $\mathrm{LUMO}_{\text {dienophile }}$ is comparatively low, thus the reaction proceeds with normal electron demand [68].

Table 4

Chemical hardness ( $\eta)$, softness (S), electronic chemical potential $(\mu)$, electrophilicity index $(\omega)$ and nucleophilicity index $(\mathrm{N})$ for all species in scheme 1

\begin{tabular}{|llllll|}
\hline Chemical Species & $\boldsymbol{\eta}$ & $\mathbf{S}$ & $\boldsymbol{\mu}$ & $\boldsymbol{\omega}$ & $\mathbf{N}$ \\
\hline 2a & 4.06 & 0.25 & -6.42 & 5.08 & 0.42 \\
\hline a & 3.01 & 0.33 & -3.85 & 2.46 & 4.05 \\
\hline TS1a & 2.62 & 0.38 & -4.11 & 3.22 & 4.17 \\
\hline 3a & 2.69 & 0.37 & -4.14 & 3.18 & 4.08 \\
\hline TS2a & 1.64 & 0.61 & -3.64 & 4.02 & 5.62 \\
\hline 4a & 1.94 & 0.52 & -4.09 & 4.31 & 4.88 \\
\hline TS3a & 1.78 & 0.56 & -3.53 & 3.49 & 5.60 \\
\hline 5a & 3.11 & 0.32 & -4.1 & 2.70 & 3.68 \\
\hline TS4a & 2.71 & 0.37 & -4.106 & 3.11 & 4.09 \\
\hline $6 a$ & 3.25 & 0.31 & -4.108 & 2.59 & 3.54 \\
\hline
\end{tabular}

In Table 4, values of global reactivity descriptors are listed for all structures of scheme 1 . Chemical hardness $(\eta)$ basically explains structural polarization of electronic cloud and it also signifies the resistance of molecules/atoms/ions to the deformation under little perturbation during a chemical reaction. Chemical softness $(S)$ is the reciprocal of chemical hardness and it is defined as the ability of 
an atom or molecule to receive the electrons. Usually, soft molecules have smaller gap between $\mathrm{E}_{\mathrm{HOMO}}$ and $E_{\text {LUMO }}$ as compared to hard molecules [45]. Relations used for estimation of $\eta$ and $S$ are given in computational details. Among the reactants, maleic anhydride is harder as compared to $7 \mathrm{H}$ benzo[a]phenalene. Hardness of product (6a) is greater than all intermediates which shows that product (6a) is more resistant to react further. It should be noted that softness of each transition state is greater than corresponding minima structures. For example, TS4a is softer as compared to $6 a$ and $5 a$.

Eq 4 has been used for the calculation of chemical potential $(\mu)$ which provided information about the charge transfer among reacting molecules [64]. As indicated in Table 4, the value of chemical potential for $7 H$ benzo[a]phenalene is greater than maleic anhydride which means that significant amount of charge will transferred form diene (7H-benzo[a]phenalene) to dienophile (maleic anhydride) $[69,70]$. To get an idea about the abilities of molecules to accept electrons, electrophilicity index was calculated. It is one of the most significant descriptors of conceptual DFT which enables us to understand and predict physiochemical processes [71]. If value of electrophilicity index increases beyond $1.5 \mathrm{eV}$ for a given species then it is regarded as strong electrophile [68]. According to this principle all structures listed in Table 4 are strong electrophiles. Important point is the fact that $\omega$ is much higher for maleic anhydride $(5.08 \mathrm{eV})$ than $7 H$-benzo[a]phenalene $(2.46 \mathrm{eV})$ which also confirms that dienophile is acting as electrophile in this reaction [68].

Nucleophilicity index $(\mathrm{N})$ which is computed by using eq 5 , is related directly to polarizability and inversely to effective nuclear charge [72]. As expected, value of $\mathrm{N}$ is greater for diene as compared to dienophile which is also favors the interaction of HOMO of diene with LUMO of dienophil [68]. $\mathrm{N}$ and $\omega$ are powerful quantum chemical tools which not only tell about interaction of frontier molecular orbitals, but also predict feasibility and polar character of Diels-Alder reactions i.e. for a reaction to be more polar and faster the diene should be more nucleophilic and dinophile should be more electrophilic or vice versa [35]. Thus, from values of $\mathrm{N}$ and $\omega$ the polar nature of this cycloaddition reaction (between 1a and 2a) could be predicted.

Table 5

NBO charges on selected atoms of reactants and product in scheme 1 (Unit of charge is e)

\begin{tabular}{|cccccc|}
\hline & C1 & C2 & C18 & C20 & 04 \\
\hline $2 a$ & -0.243 & -0.243 & & & -0.564 \\
\hline $1 a$ & & & -0.201 & -0.167 & \\
\hline $6 a$ & -0.327 & -0.337 & -0.043 & -0.021 & -0.558 \\
\hline
\end{tabular}

Natural bond orbital (NBO) analysis provides insight into chemical bond properties and electronic properties of molecules [73]. This analysis is directly related to electronic wave functions and is based upon unoccupied Non-Lewis and occupied Lewis localized orbitals [45]. NBO analysis provides best 
possible picture of natural Lewis structure, because fine details of orbitals are chosen mathematically for the inclusion of highest possible electron density [74].

As indicated in Table 5, C1 and C2 (atoms of maleic anhydride) have an equal amount of charge in the reactant, however, in the product these two atoms have slight variation in their charges. Charges on $\mathrm{C} 18$ and $\mathrm{C} 20$ changes from -0.201 and -0.167 to -0.043 and -0.021 respectively. While charges on $\mathrm{C} 1$ and $\mathrm{C} 2$ are varied from -0.243 each to -0.327 and -0.337 respectively. These values of charges on the selected atoms clearly reveal the transfer of charge from $1 \mathrm{a}$ to $2 \mathrm{a}$ [75]. Charge on oxygen atom does not show any significant variation in its value.

Fukui functions are the quantitative descriptors used to rationalize the chemical reactivity at a particular site of molecule [76]. These functions were proposed by Parr and Yang and defined as "the partial derivative of electron density with respect to total number of electrons of the system at constant external pressure" [77]. These are calculated according to eq 6 and eq 7 by using natural population.

Table 6 Condensed to atom Fukui $(\mathrm{f}+)$ functions for maleic anhydride (2a)

\begin{tabular}{|llllllll|}
\hline Atom & C1 & C2 & C3 & C5 & 04 & 06 & 07 \\
\hline $\mathrm{f}+$ & 0.19 & 0.19 & 0.065 & 0.065 & 0.036 & 0.18 & 0.18 \\
\hline
\end{tabular}

Parr and Yang also indicated that the sites in molecules which have largest values of Fukui functions are most reactive for the attack of electrophile/nucleophile [74]. The condensed to atoms Fukui functions ( $f+$ ) for all carbon and oxygen atoms of $2 \mathrm{a}$ are calculated, results are reported in Table 6 . It is clear from this table that $\mathrm{C} 1$ and $\mathrm{C} 2$ are the most reactive sites for attack of 1a (nucleophile). As $7 H$-benzo[a]phenalene is behaving as nucleophile, therefore, "f-" have been calculated for locating the sites of attack by electrophile. Values of these functions on all carbon atoms of $7 H$-benzo[a]phenalene are given in Table 7. 
Table 7

Condensed to atom Fukui (f-)

functions for $7 H$-benzo[a]phenalene

(1a)

\begin{tabular}{|llll|}
\hline Atom & $\mathbf{f}-$ & Atom & $\mathbf{f}-$ \\
\hline C10 & 0.026 & $\mathbf{C 1 9}$ & 0.048 \\
C11 & 0.052 & $\mathbf{C 2 0}$ & 0.418 \\
\hline C12 & 0.027 & $\mathbf{C 2 1}$ & 0.091 \\
\hline C13 & 0.104 & $\mathbf{C 2 2}$ & 0.137 \\
\hline C14 & 0.037 & $\mathbf{C 2 3}$ & 0.031 \\
\hline C15 & 0.048 & $\mathbf{C 2 4}$ & 0.02 \\
\hline C16 & 0.029 & $\mathbf{C 2 5}$ & 0.723 \\
\hline C17 & 0.064 & $\mathbf{C 2 6}$ & 0.656 \\
\hline C18 & 0.069 & & \\
\hline
\end{tabular}

Now, the effect electron withdrawing and electron donating substituents is determined on reaction mechanism. The substituent selected as an electron withdrawing species is the chlorine. In maleic anhydride, the bond distances of $\mathrm{C} 2-\mathrm{C} 5$ and $\mathrm{C} 1-\mathrm{C} 3$ are equal i.e. $1.49 \AA$, but their values changed to $1.487 \AA$ and $1.506 \AA ̊$ in chloro maleic anhydride, respectively. Values of $8,1,2$ and $9,2,5$ bond angles also differ slightly in chloro maleic anhydride.

Introduction of chlorine on carbon 2 of maleic anhydride caused its energy to reduce by an amount of 460 Hartree. Enthalpy and free energy are also decreased by a similar amount. However, entropy in case of chloro maleic anhydride is higher than the entropy of maleic anhydride. The former has an entropy of $81 \mathrm{cal} / \mathrm{mol} / \mathrm{K}$, this value is $8 \mathrm{cal} / \mathrm{mol} / \mathrm{K}$ greater than the entropy of latter. Discussion of these thermodynamic parameters indicates that the chlorine substituent has enhanced the overall stability of the structure.

Next, the effect of this substituent on the energies of frontier orbitals has been analyzed. Influence of chlorine on $\mathrm{E}_{\mathrm{HOMO}}$ and $\mathrm{E}_{\mathrm{LUMO}}$, as one can realize by comparison of Fig. 5 and Fig. 6 , is completely opposite. $\mathrm{E}_{\text {HOMO }}$ is increased by $0.15 \mathrm{eV}$ while $\mathrm{E}_{\mathrm{LUMO}}$ is decreased by $0.19 \mathrm{eV}$. $\mathrm{E}_{\mathrm{LUMO}}$-HOMO have been reduced from $8.1 \mathrm{eV}$ to $7.8 \mathrm{eV}$. In order to check if the reaction is still NED or it has changed to IED following energies are computed:

$\mathrm{HOMO}_{\text {dienophile }}-\mathrm{LUMO}_{\text {diene }}=9.5 \mathrm{eV}$

$\mathrm{LUMO}_{\text {dienophhile }}-\mathrm{HOMO} \mathrm{O}_{\text {diene }}=4.3 \mathrm{eV}$ 
These values shows that not only the reaction is normal electron demand, in fact the interactions of frontier orbitals are now more favorable. Usually, it is expected that under such circumstances it becomes easier for reacting species to undergo reaction and activation barrier becomes lower. But this is not the case in study of present reaction. From Table 8 , it can be seen that activation barrier became considerably high by the substitution of chlorine on maleic anhydride.

Table 8

Thermodynamic parameters for reaction B (scheme 2$)$ at M06-2x++(d,p) level

\begin{tabular}{|lllll|}
\hline Structure & $\begin{array}{l}\Delta \mathrm{H} \\
(\mathrm{kcal} / \mathrm{mol})\end{array}$ & $\begin{array}{l}\Delta \mathrm{S} \\
\left(\mathrm{Calmol}^{-1} \mathrm{~K}^{-1}\right)\end{array}$ & $\begin{array}{l}\Delta \mathrm{G} \\
(\mathrm{kcal} / \mathrm{mol})\end{array}$ & $\begin{array}{l}\Delta \mathrm{E} \\
(\mathrm{kcal} / \mathrm{mol})\end{array}$ \\
\hline 1a+2b & 0 & 0 & 0 & 0 \\
\hline TS1b & 38.12 & -47.95 & 52.42 & 38.4 \\
\hline 3b & 9.63 & -51.66 & 25.03 & 7.4 \\
\hline
\end{tabular}

This unusual behavior can be attributed to the much higher stability of chloro maleic anhydride as compared to the maleic anhydride as discussed above. According to L.J. Andrews and R.L Keefer following resonance structure is responsible for this increased stability of chloro maleic anhydride [23]:

Another possible reason for the elevated reaction barrier of reaction B as compared to reaction $A$, could be the increase in steric hindrance due replacement of hydrogen by the chlorine [78].

Next it is investigated whether the polarity and charge transfer of reaction has been altered or not. For this purpose, the global reactivity indices computed from energies of frontier orbitals are provided in Table 9.

Table 9

Global reactivity indices for reaction $B$ (scheme 2) at M06-2x $6311++(\mathrm{d}, \mathrm{p})$ level

\begin{tabular}{|llllll|}
\hline Chemical Species & $\boldsymbol{\eta}$ & $\mathbf{S}$ & $\boldsymbol{\mu}$ & $\boldsymbol{\omega}$ & $\mathbf{N}$ \\
\hline 2b & 3.89 & 0.26 & -6.44 & 5.33 & 0.57 \\
\hline TS1b & 1.49 & 0.67 & -5.08 & 8.62 & 4.32 \\
\hline 3b & 2.69 & 0.37 & -4.19 & 3.27 & 4.01 \\
\hline
\end{tabular}

From the Table 9 and Table 4, it can be concluded that the reaction is polar in nature and charge is being transferred from diene to dienophile.

MESP of chloro maleic anhydride reveals that electron density on C2 is increased to some extent, as this region is now green instead of blue. Analysis of natural charges indicate that chlorine caused the negative charges of oxygen atoms to reduce and negative charge of $\mathrm{C} 1$ to increase. This increase in 
negative potential of $\mathrm{C} 1$ and $\mathrm{C} 2$ could also be the reason behind increased barrier for the reaction because in such situation chances of attack of nucleophile gets decreased.

Fukui indices are computed for chloro maleic anhydride, in order to see weather, the most reactive sites have been changed or not.

Table 10

Condensed to atom Fukui ( $f+$ ) functions for chloro

maleic anhydride $(2 \mathrm{~b})$

\begin{tabular}{|llllll|}
\hline Atom & C1 & C2 & C3 & C5 & 04 \\
\hline $\mathrm{f}+$ & 0.176 & 0.14 & 0.06 & 0.069 & 0.032 \\
\hline
\end{tabular}

According to values provided in Table 10, still the most suitable carbons for the attack of nucleophile are $\mathrm{C} 1$ and $\mathrm{C} 2$. Their ability to get attacked by diene is although somewhat reduced which could be due to electron withdrawing nature of chlorine. This is in consistent with the results of MESP and natural atomic charges.

For knowing the effects of electron donating group on this particular reaction, mechanism of citraconic anhydride with $7 \mathrm{H}$-benzo[a]phenalene is determined. Stability of maleic anhydride is increased on the substitution of methyl group but this time it is stabilized by just 39 Hartree. From Table 11 it can be seen that rise in activation barrier in this case is much higher. This increase in stability cannot justify the increase in activation barrier because increase in stability of chloro maleic anhydride was more than citraconic anhydride but in case of former rise in activation energy was lower.

Table 11

Thermodynamic parameters for reaction C (scheme 3) at M06-2x++(d,p) level

\begin{tabular}{|lllll|}
\hline Structure & $\begin{array}{l}\Delta H \\
(\mathrm{kcal} / \mathrm{mol})\end{array}$ & $\begin{array}{l}\Delta \mathrm{S} \\
\left(\mathrm{Calmol}^{-1} \mathrm{~K}^{-1}\right)\end{array}$ & $\begin{array}{l}\Delta \mathrm{G} \\
(\mathrm{kcal} / \mathrm{mol})\end{array}$ & $\begin{array}{l}\Delta \mathrm{E} \\
(\mathrm{kcal} / \mathrm{mol})\end{array}$ \\
\hline 1a+2c & 0 & 0 & 0 & 0 \\
\hline TS1c & 70.13 & -50.16 & 85.08 & 70.6 \\
\hline 3c & 15.24 & -53.80 & 31.28 & 12.9 \\
\hline
\end{tabular}

Comparison of Fig. 5 and Fig. 8 reveals that in citraconic anhydride energy of LUMO is higher as compared to maleic anhydride thus the gap of $\mathrm{LUMO}_{\text {dienopile }}$ and $\mathrm{HOMO}_{\text {diene }}$ has been increased to $4.8 \mathrm{eV}$, it has made the interactions of these frontier orbitals difficult. Hence, activation energy for the reaction is enhanced to such a large value. 
Table 12

Global reactivity indices for structures in scheme 3 at M062X $6311++(d, p)$ level

\begin{tabular}{|llllll|}
\hline Chemical Species & $\boldsymbol{\eta}$ & $\mathbf{S}$ & $\boldsymbol{\mu}$ & $\boldsymbol{\omega}$ & $\mathbf{N}$ \\
\hline 2c & 4.11 & 0.24 & -6.18 & 4.65 & 0.61 \\
\hline TS1c & 1.31 & 0.76 & -4.84 & 8.94 & 4.75 \\
3c & 2.70 & 0.37 & -4.10 & 3.11 & 4.10 \\
\hline
\end{tabular}

Hardness of methyl maleic anhydride is higher than the hardness of both chloro maleic anhydride and maleic anhydride, which may also be linked to highest barrier of the reaction $C$ (scheme 3 ). Its electrophilicity index is lower than those of other two anhydrides. As discussed before the reaction in which electrophile has higher value of electrophilicity index are more polar. This shows that this reaction is less polar as compared to other two reactions.

Fukui functions computed for citraconic anhydride are provided in Table 13. Just like the other two anhydrides, $\mathrm{C} 1$ and $\mathrm{C} 2$ are the carbons with highest probability of attack by diene.

Table 13

Condensed to atom Fukui $(\mathrm{f}+)$ functions for citraconic anhydride (2c)

\begin{tabular}{|llllll|}
\hline Atom & C1 & C2 & C3 & C5 & 04 \\
\hline $\mathrm{f}+$ & 0.167 & 0.17 & 0.067 & 0.077 & 0.031 \\
\hline
\end{tabular}

Methyl group did not cause sufficient increase in negative potential of C2 like chlorine, as evident by the comparison of Fig. 9 and Fig. 7.

Polarity of reaction can also be rationalized by the calculation of global electron density transfer (GEDT) at transition sate of the reaction. GEDT at the transition states of cycloaddition step for all reactions are computed by using the following relation [79]:

GEDT $=-\sum q_{A}$

$\mathrm{q}_{\mathrm{A}}$ is the charge on atoms of diene fragment of transition state. According to GEDT, reaction of methyl maleic anhydride is least polar. This is in consistent with the results of electrophilicity index.

\section{Conclusion}

In conclusion, the effects of chlorine and methyl group on reaction of maleic anhydride with $7 \mathrm{H}$ benzo[a]phenalene have been determined. In the absence of any substituent, activation energy of cycloaddition was found to be $9.3 \mathrm{kcal} / \mathrm{mol}$ only. Methyl group, behaving as an electron donating group, increased the gap of $\mathrm{LUMO}_{\text {dienophile }}$ and $\mathrm{HOMO}_{\text {diene. }}$. As a consequence, interactions of these frontier orbitals became difficult and activation energy for this reaction was raised. Polarity of the reaction got 
reduced, as indicated by the GEDT at transition state. On the other hand, chorine is an electron withdrawing group. It lowered the energy of lowest unoccupied orbital of dienophile and resultantly decreased the $\mathrm{LUMO}_{\text {dienophile }}-\mathrm{HOMO}_{\text {diene }}$ gap. This lowered gap should have resulted in more favorable interactions of these orbitals thus reducing the energy barrier which did not happen because substitution of chlorine stabilized the maleic anhydride by a large amount of energy and reduced the reactivity of maleic anhydride towards $7 H$-benzo[a]phenalene. Resultantly, activation energy increased to 38.4 $\mathrm{kcal} / \mathrm{mol}$ for reaction $\mathrm{B}$. MESP indicated that negative potential of reactive sites of the chloro maleic anhydrides is more as compared to maleic anhydride and fukui functions revealed that ability of these sites to get attacked by nucleophile is decreased, these factors could also be a reason behind increased activation barrier. Additionally, steric hindrance can also have contribution to this rise in the barrier as hydrogen has been replaced by bulkier atom of chlorine. Results of our computational study are in accordance with experimental observations.

\section{Declarations}

\section{Funding:}

A.M is grateful to Higher Education Commission (HEC) Pakistan for providing financial support for this study (NRPU/5613).

\section{Conflicts of Interest/Competing Interest:}

The authors have no conflict of interest or any sort of competing interest.

\section{Availability of Data and Materials:}

All the relevant data and materials are available and can be provided as per requirement.

\section{Code Availability:}

Not Applicable.

\section{Authors' Contributions:}

All authors contributed to the study conception and design. Material preparation, data collection and analysis were performed by [Umatur Rehman], [Asim Mansha], [Muhammad Zahid], [Sadia Asim] and [Zulfiqar Ahmad Rehan]. The first draft of the manuscript was written by [Ameer Fawad Zahoor], [Asim Mansha] and all authors commented on previous versions of the manuscript. All authors read and approved the final manuscript.

\section{References}


1. L. Merzoud, F. Guégan, H. Chermette, C. Morell, Understanding the intermolecular Diels-Alder cycloaddition promotion: Activation strain model/energy decomposition analysis model and conceptual density functional theory viewpoints, Journal of computational chemistry 42 (2021) 1364-1372.

2. W.K. Samba, R. Tia, E. Adei, Regio-, enantio-, peri-, and stereo-selectivities of the reactions of fivemembered cyclodiene derivatives with itaconic anhydride toward the formation of norbornene lactones, Journal of Physical Organic Chemistry 34(2) (2021) e4132.

3. T.S. Khan, S. Gupta, M. Ahmad, M.I. Alam, M.A. Haider, Effect of substituents and promoters on the Diels-Alder cycloaddition reaction in the biorenewable synthesis of trimellitic acid, RSC Advances 10(51) (2020) 30656-30670.

4. A. Oluwasanmi, C. Hoskins, Potential use of the Diels-Alder reaction in biomedical and nanomedicine applications, International Journal of Pharmaceutics (2021) 120727.

5. N.S. Medrán, F. Dezotti, S.C. Pellegrinet, Remarkable Reactivity of Boron-Substituted Furans in the Diels-Alder Reactions with Maleic Anhydride, Organic letters 21(13) (2019) 5068-5072.

6. M.A. Sultan, U. Karama, Substituent effects on regioselectivity of the Diels-Alder reactions: Reactions of 10-allyl-1, 8-dichloroanthracene with 2-chloroacrylonitrile, 1-cyanovinyl acetate and phenyl vinyl sulfone, Journal of Chemistry 2016 (2016) 1-5.

7. L. Rulíšek, P. Šebek, Z. Havlas, R. Hrabal, P. Čapek, A. Svatoš, An experimental and theoretical study of stereoselectivity of furan- maleic anhydride and furan- maleimide Diels- Alder reactions, The Journal of organic chemistry 70(16) (2005) 6295-6302.

8. W.J. Lording, T. Fallon, M.S. Sherburn, M.N. Paddon-Row, The simplest Diels-Alder reactions are not endo-selective, Chemical science 11(43) (2020) 11915-11926.

9. C.J. Cole, L. Fuentes, S.A. Snyder, Asymmetric pyrone Diels-Alder reactions enabled by dienamine catalysis, Chemical science 11(8) (2020) 2175-2180.

10. M. El Ghozlani, A. Barhoumi, R. Elkacmi, A.O. Aitouna, A. Zeroual, M. El Idrissi, Mechanistic Study of Hetero-Diels-Alder [4+ 2] Cycloaddition Reactions Between 2-Nitro-1H-Pyrrole and Isoprene, Chemistry Africa 3(4) (2020) 901-909.

11. R. Gara, M.O. Zouaghi, L.M.H. ALshandoudi, Y. Arfaoui, DFT investigation of solvent, substituent, and catalysis effects on the intramolecular Diels-Alder reaction, Journal of molecular modeling $27(5)$ (2021) 1-12.

12. S. Yoshioka, H. Aoyama, H. Fujioka, M. Arisawa, Cascade Multiple Diels-Alder Reactions of Styrene Derivatives with Maleimide or Maleic Anhydride, The Journal of organic chemistry 83(12) (2018) 6599-6606.

13. M. Mojica, F. Méndez, J.A. Alonso, The Diels-Alder cycloaddition reaction of substituted hemifullerenes with 1, 3-butadiene: Effect of electron-donating and electron-withdrawing substituents, Molecules 21(2) (2016) 200.

14. L. Mahardiani, A. Shrotri, H. Kobayashi, A. Fukuoka, Structure and activity of activated carbon functionalized with maleic anhydride by diels-alder reaction, Catalysis Today 357 (2020) 409-415. 
15. A. Khorief Nacereddine, L. Merzoud, C. Morell, H. Chermette, A computational investigation of the selectivity and mechanism of the Lewis acid catalyzed oxa-Diels-Alder cycloaddition of substituted diene with benzaldehyde, Journal of computational chemistry 42(18) (2021) 1296-1311.

16. M. Kořenková, V. Kremláček, M. Hejda, J. Turek, R. Khudaverdyan, M. Erben, R. Jambor, A. Růžička, L. Dostál, Hetero Diels-Alder Reactions of Masked Dienes Containing Heavy Group 15 Elements, Chemistry-A European Journal 26(5) (2020) 1144-1154.

17. M. Sahrane, K. Marakchi, R. Ghailane, Theoretical study of the Diels-Alder reaction of 3-bromo-1phenylprop-2-ynone with furan and 2-methylfuran, Theoretical Chemistry Accounts 140(8) (2021) 110.

18. A. Kącka-Zych, R. Jasiński, Molecular mechanism of Hetero Diels-Alder reactions between (E)-1, 1, 1trifluoro-3-nitrobut-2-enes and enamine systems in the light of Molecular Electron Density Theory, Journal of Molecular Graphics and Modelling 101 (2020) 107714.

19. H. Hall Jr, P. Nogues, J. Rhoades, R. Sentman, M. Detar, (Carbomethoxy) maleic anhydride, a highly reactive new dienophile and comonomer, The Journal of organic chemistry 47(8) (1982) 1451-1455.

20. K. Sakata, H. Fujimoto, Origin of the endo Selectivity in the Diels-Alder Reaction between Cyclopentadiene and Maleic Anhydride, European Journal of Organic Chemistry 2016(25) (2016) 4275-4278.

21. W. Jia, Z. Si, Y. Feng, X. Zhang, X. Zhao, Y. Sun, X. Tang, X. Zeng, L. Lin, Oxidation of 5-[(Formyloxy) methyl] furfural to maleic anhydride with atmospheric oxygen using a-MnO2/Cu (NO3) 2 as catalysts, ACS Sustainable Chemistry \& Engineering 8(21) (2020) 7901-7908.

22. V.N. Huynh, M. Leitner, A. Bhattacharyya, L. Uhlstein, P. Kreitmeier, P. Sakrausky, J. Rehbein, O. Reiser, Diels-Alder reactions and electrophilic substitutions with atypical regioselectivity enable functionalization of terminal rings of anthracene, Communications Chemistry 3(1) (2020) 1-9.

23. L. Andrews, R. Keefer, A Kinetic Study of the Diels-Alder Reaction of Various Anthracene and Maleic Anhydride Derivatives, Journal of the American Chemical Society 77(23) (1955) 6284-6289.

24. L.J. Karas, A.T. Campbell, I.V. Alabugin, J.I. Wu, Antiaromaticity Gain Activates Tropone and Nonbenzenoid Aromatics as Normal-Electron-Demand Diels-Alder Dienes, Organic letters 22(18) (2020) 7083-7087.

25. A. Atalay, R. Abbasoglu, Theoretical investigation on facial and stereoselectivity in Diels-Alder cycloadditions of maleic anhydride to dissymmetric cage-annulated cyclohexa-1, 3-dienes, Journal of Physical Organic Chemistry 32(2) (2019) e3893.

26. C.A. Stewart Jr, Diene Structure and Diels-Alder Reactivity, The Journal of organic chemistry 28(12) (1963) 3320-3323.

27. M.E. Welker, Boron and Silicon-Substituted 1, 3-Dienes and Dienophiles and Their Use in Diels-Alder Reactions, Molecules 25(16) (2020) 3740.

28. A.L. Dewyer, \& Zimmerman, P. M., Finding reaction mechanisms, intuitive or otherwise, Org. Biomol. Chem 15(3) (2017) 501-504. 
29. D.A. Akuamoah, R. Tia, E. Adei, Computational study on the mechanism of the reaction of benzenesulfonyl azides with oxabicyclic alkenes, Journal of molecular modeling 26(11) (2020) 1-9.

30. M. Ahraminejad, R. Ghiasi, B. Mohtat, R. Ahmadi, Computational investigation of the substituent effect in the [2+ 4] Diels-Alder cycloaddition reactions of $\mathrm{HSi} \equiv \mathrm{Si}$ (para-C6H4X) with benzene, Journal of the Chinese Chemical Society 68 (2021) 806-816.

31. I. Funes-Ardoiz, F. Schoenebeck, Established and emerging computational tools to study homogeneous catalysis-From quantum mechanics to machine learning, Chem 6(8) (2020) 19041913.

32. K. Abbiche, N. Acharjee, M. Salah, M. Hilali, A. Laknifli, N. Komiha, K. Marakchi, Unveiling the mechanism and selectivity of [3+2] cycloaddition reactions of benzonitrile oxide to ethyl transcinnamate, ethyl crotonate and trans-2-penten-1-ol through DFT analysis, Journal of molecular modeling 26(10) (2020) 1-12.

33. M.R.J.-C.K.G.N.C. Rice, Benzanthrone compounds and antiviral uses thereof, US Department of Health and Human Services Trimeris Inc, 2000, July 26.

34. S.M. Bakalova, A.G. Santos, A Computational Study of the Diels- Alder Reaction of Ethyl-S-lactyl Acrylate and Cyclopentadiene. Origins of Stereoselectivity, The Journal of organic chemistry 69(24) (2004) 8475-8481.

35. L.R. Domingo, M. Ríos-Gutiérrez, P. Pérez, A molecular electron density theory study of the participation of tetrazines in aza-Diels-Alder reactions, RSC Advances 10(26) (2020) 15394-15405.

36. S. Uzun, Z. Esen, E. Koç, N.C. Usta, M. Ceylan, Experimental and density functional theory (MEP, FMO, NLO, Fukui functions) and antibacterial activity studies on 2-amino-4-(4-nitrophenyl)-5, 6dihydrobenzo [h] quinoline-3-carbonitrile, Journal of Molecular Structure 1178 (2019) 450-457.

37. T. Salavati-fard, S. Caratzoulas, D.J. Doren, DFT Study of Solvent Effects in Acid-Catalyzed DielsAlder Cycloadditions of 2, 5-Dimethylfuran and Maleic Anhydride, The Journal of Physical Chemistry A 119(38) (2015) 9834-9843.

38. J.P. Hernández-Mancera, F. Núñez-Zarur, R. Vivas-Reyes, Diels-Alder Reactivity of a Chiral Anthracene Template with Symmetrical and Unsymmetrical Dienophiles: A DFT Study, ChemistryOpen 9(7) (2020) 748.

39. M.D. Singh, A. Ningombam, High stereoselectivity in the Diels-Alder reaction of substituted anthracenes: Reactions of 1-succinimidoanthracene and 1-phthalimidoanthracene with maleic anhydride, Indian Journal of Chemistry 49 (2010) 789-794.

40. M.C. Kloetzel, The Diels-Alder Reaction with Maleic Anhydride, Organic Synthesis2011, March 15, pp. 30-31.

41. M. Linder, T. Brinck, On the method-dependence of transition state asynchronicity in Diels-Alder reactions, Physical chemistry chemical physics: PCCP 15(14) (2013) 5108-14.

42. J.P. Hernandez Mancera, F. Nunez-Zarur, S. Gutierrez-Oliva, A. Toro-Labbe, R. Vivas-Reyes, Diels-Alder reaction mechanisms of substituted chiral anthracene: $A$ theoretical study based on the reaction force and reaction electronic flux, Journal of computational chemistry 41(23) (2020) 2022-2032. 
43. K.J. Kron, M. Kosich, R.J. Cave, D.A. Vosburg, Divergent Diels-Alder Reactions in the Biosynthesis and Synthesis of Endiandric-Type Tetracycles: A Computational Study, The Journal of organic chemistry 83(18) (2018) 10941-10947.

44. R. Jasiński, $\beta$-Trifluoromethylated nitroethenes in Diels-Alder reaction with cyclopentadiene: A DFT computational study, Journal of Fluorine Chemistry 206 (2018) 1-7.

45. Z. Fakhar, T. Govender, G. Lamichhane, G.E.M. Maguire, H.G. Kruger, B. Honarparvar, Computational model for the acylation step of the $\beta$-lactam ring: Potential application for I,d-transpeptidase 2 in mycobacterium tuberculosis, Journal of Molecular Structure 1128 (2017) 94-102.

46. L.R. Domingo, M. Ríos-Gutiérrez, P. Pérez, How does the global electron density transfer diminish activation energies in polar cycloaddition reactions? A Molecular Electron Density Theory study, Tetrahedron 73(13) (2017) 1718-1724.

47. S.M. Bakalova, Kaneti, J., \& Markova, N., Computational study of exo-selective Diels-Alder cycloadditions, catalyzed by aluminum chloride, 49 (2017) 195-200.

48. D. Yepes, P. Pérez, P. Jaque, I. Fernández, Effect of Lewis acid bulkiness on the stereoselectivity of Diels-Alder reactions between acyclic dienes and a, $\beta$-enals, Organic Chemistry Frontiers 4(7) (2017) 1390-1399.

49. P. Bandyopadhyay, S. Ray, M.M. Seikh, Unraveling the regioselectivity of odd electron halogen bond formation using electrophilicity index and chemical hardness parameters, Physical chemistry chemical physics: PCCP 21(48) (2019) 26580-26590.

50. R. Jasinski, E. Jasinska, E. Dresler, A DFT computational study of the molecular mechanism of [3 + 2] cycloaddition reactions between nitroethene and benzonitrile $\mathrm{N}$-oxides, Journal of molecular modeling 23(1) (2017) 13.

51. R. Jasinski, One-step versus two-step mechanism of Diels-Alder reaction of 1-chloro-1-nitroethene with cyclopentadiene and furan, Journal of molecular graphics \& modelling 75 (2017) 55-61.

52. T. Afshari, M. Mohsennia, A molecular electron density theory study of Diels-Alder reaction between Danishefsky's diene and (2E)-3-phenyl-2-(trifluoromethyl) acrylonitrile, Journal of Physical Organic Chemistry 32(6) (2019) e3937.

53. F. De Proft, C. Van Alsenoy, A. Peeters, W. Langenaeker, P. Geerlings, Atomic charges, dipole moments, and Fukui functions using the Hirshfeld partitioning of the electron density, Journal of computational chemistry 23(12) (2002) 1198-209.

54. J.M. Ali, T.A. Lelisho, Chemical fixation of CO2 with propylene oxide catalyzed by Trimethylsulfonium bromide in the presence of $\mathrm{HBr}$ : a computational study, Theoretical Chemistry Accounts 139(10) (2020) 1-10.

55. M. Soleymani, DFT study of double 1,3-dipolar cycloaddition of nitrilimines with allenoates, Monatshefte für Chemie - Chemical Monthly 149(12) (2018) 2183-2193.

56. M.J. Hoque, Ahsan, A., \& Hossain, M. B., Molecular Docking, Pharmacokinetic, and DFT Calculation of Naproxen and its Degradants, Biomedical Journal of Scientific \& Technical Research 9(5) (2018) $7360-7365$. 
57. J. Schmauck, M. Breugst, The potential of pnicogen bonding for catalysis - a computational study, Organic \& biomolecular chemistry 15(38) (2017) 8037-8045.

58. M. Soleymani, Theoretical study on the [4+2] cycloaddition of 1,3-dimethylindole with 2,6dimethylquinone, Structural Chemistry 30(4) (2019) 1173-1184.

59. J. Andrés, Berski, S., \& Silvi, B, Curly arrows meet electron density transfers in chemical reaction mechanisms: from Electron Localization Function (ELF) analysis to valence-shell electron-pair repulsion (VSEPR) inspired interpretationt, Chem. Commun 52(53) (2016) 8183-8195.

60. M.M. Lawal, T. Govender, G.E.M. Maguire, H.G. Kruger, B. Honarparvar, DFT study of the acidcatalyzed esterification reaction mechanism of methanol with carboxylic acid and its halide derivatives, International Journal of Quantum Chemistry 118(4) (2018) e25497.

61. S.A. Grimmel, M. Reiher, The electrostatic potential as a descriptor for the protonation propensity in automated exploration of reaction mechanisms, Faraday discussions 220(0) (2019) 443-463.

62. T.R. Patel, B. Ganguly, Revealing the Origin of $\Pi$-facial and Regioselectivity in the Diels-Alder Reaction of Unsymmetrical, Cage-annulated 1,3-Cyclohexadiene with Ethyl Propiolate Dienophile: a DFT Study, ChemistrySelect 5(43) (2020) 13524-13529.

63. K.S. Sandhya, \& Suresh, C. H., Designing metal hydride complexes for water splitting reactions: A molecular electrostatic potential approach, Dalton Trans 43(32) (2014) 12279-12287.

64. U. Nazeer, N. Rasool, A. Mujahid, A. Mansha, M. Zubair, N. Kosar, T. Mahmood, A. Raza Shah, S.A.A. Shah, Z.A. Zakaria, M.N. Akhtar, Selective Arylation of 2-Bromo-4-chlorophenyl-2-bromobutanoate via a Pd-Catalyzed Suzuki Cross-Coupling Reaction and Its Electronic and Non-Linear Optical (NLO) Properties via DFT Studies, Molecules 25(15) (2020) 3521.

65. A. Mubarik, N. Rasool, M.A. Hashmi, A. Mansha, M. Zubair, M.R. Shaik, M.A.F. Sharaf, E.M. Awwad, A. Abdelgawad, Computational Study of Structural, Molecular Orbitals, Optical and Thermodynamic Parameters of Thiophene Sulfonamide Derivatives, Crystals 11(2) (2021) 211.

66. F. Odame, DFT Study of the Reaction Mechanism of N-(Carbomylcarbamothioyl) Benzamide, Acta chimica Slovenica 65(2) (2018) 328-332.

67. Y. Zou, S. Yang, J.N. Sanders, W. Li, P. Yu, H. Wang, Z. Tang, W. Liu, K.N. Houk, Computational Investigation of the Mechanism of Diels-Alderase Pyrl4, Journal of the American Chemical Society 142(47) (2020) 20232-20239.

68. M.A. Sultan, U. Karama, A.I. Almansour, S.M. Soliman, Theoretical Study on Regioselectivity of the Diels-Alder Reaction between 1,8-Dichloroanthracene and Acrolein, Molecules 21(10) (2016) 1277.

69. A. Benallou, Solvent effect on Hetero-Diels-Alder reaction of isoselenazole with symmetrical acetylenic dienophiles: A MEDT study, Computational and Theoretical Chemistry 1154 (2019) 1725.

70. R.J. Hassan, H.H. Abdallah, Theoretical Study of Diels-Alder Reaction of But-3-en-2-one with Hexa1,2,4-triene: A Density Functional Theory Study, Aro-the Scientific Journal of Koya University 8(1) (2020) 74 . 
71. P. Yadav, H. Tandon, B. Malik, T. Chakraborty, A new approach to compute atomic electrophilicity index in terms of Gordy's electronegativity, Journal of Chemical Research 45(1-2) (2020) 201-206.

72. H. Tandon, T. Chakraborty, V. Suhag, A scale of atomic electronegativity in terms of atomic nucleophilicity index, Foundations of Chemistry 22(2) (2020) 335-346.

73. W. Li, C. Li, Y. Lyu, A computational mechanistic insight into $\mathrm{H} 2$ activation and $\mathrm{CO} 2$ reduction over $\beta$ Diketiminato-ligated group 13 metal complexes, Journal of Catalysis 373 (2019) 1-12.

74. Z. Demircioğlu, Ç.A. Kaştaş, O. Büyükgüngör, Theoretical analysis (NBO, NPA, Mulliken Population Method) and molecular orbital studies (hardness, chemical potential, electrophilicity and Fukui function analysis) of (E)-2-((4-hydroxy-2-methylphenylimino)methyl)-3-methoxyphenol, Journal of Molecular Structure 1091 (2015) 183-195.

75. M. Zhang, D. Wei, Y. Wang, S. Li, J. Liu, Y. Zhu, M. Tang, DFT study on the reaction mechanisms and stereoselectivities of NHC-catalyzed [2 + 2] cycloaddition between arylalkylketenes and electrondeficient benzaldehydes, Organic \& biomolecular chemistry 12(33) (2014) 6374-83.

76. M. Kour, R. Gupta, R.K. Bansal, Experimental and Theoretical Investigation of the Reaction of Secondary Amines with Maleic Anhydride, Australian Journal of Chemistry 70(12) (2017) 1247.

77. V. Pilepić, \& Uršić, S, Nucleophilic reactivity of the nitroso group. Fukui function DFT calculations for nitrosobenzene and 2-methyl-2-nitrosopropane, Journal of Molecular Structure: THEOCHEM 538(1-3) (2001) 41-49.

78. Shubin Liu, Hao Hu, L.G. Pedersen, Steric, Quantum, and Electrostatic Effects on SN2 Reaction Barriers in Gas Phase, The Journal of Physical Chemistry A 114(18) (2010) 5913-5918.

79. S.A. Siadati, N. Nami, Investigation of the possibility of functionalization of C20 fullerene by benzene via Diels-Alder reaction, Physica E: Low-dimensional Systems and Nanostructures 84 (2016) 55-59.

\section{Scheme}

See the Supplemental Files section for Scheme 1 and Scheme 2.

\section{Figures}




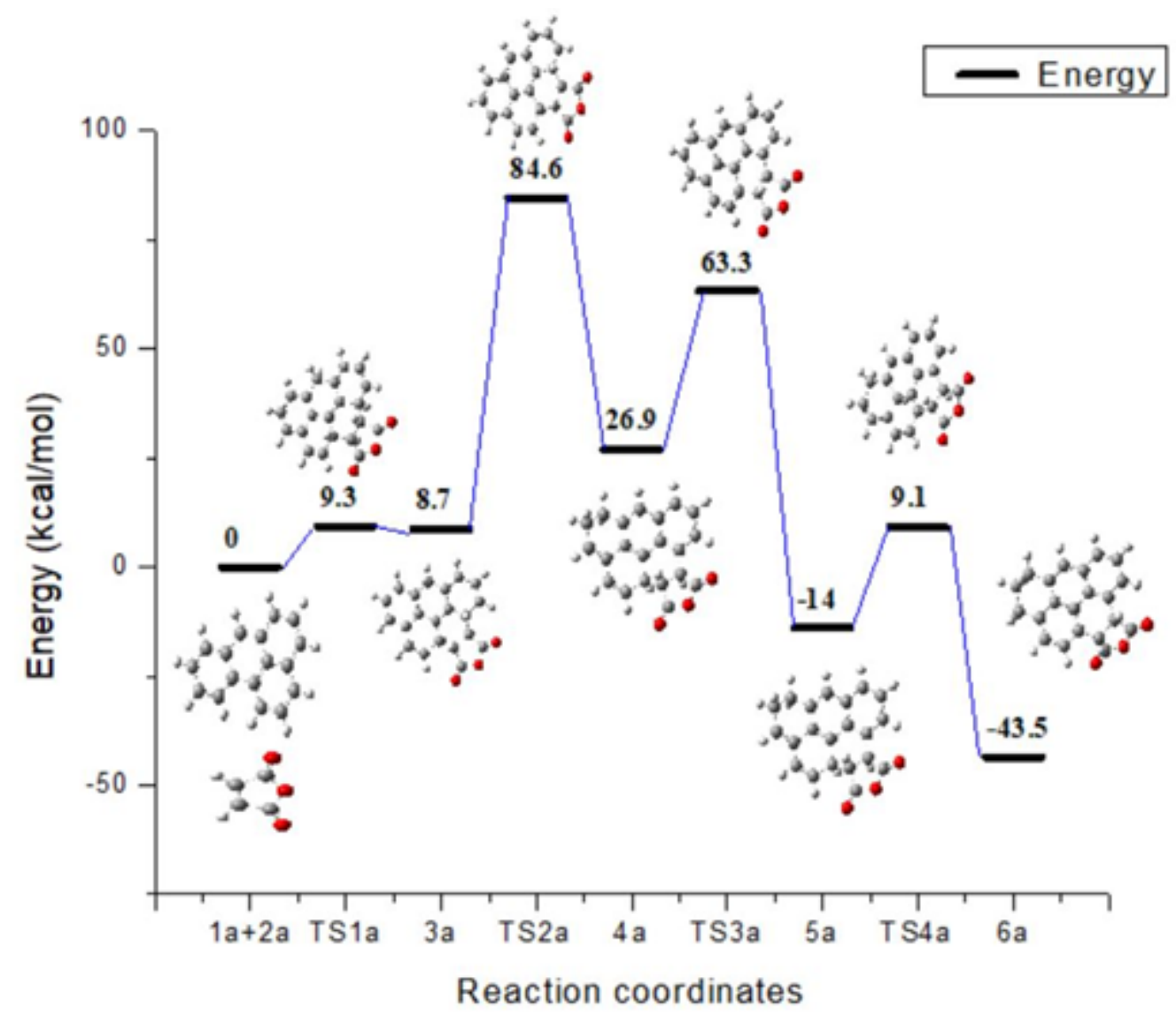

Figure 1

Potential energy surface for reaction of $7 \mathrm{H}$-benzo[a]phenalene (1a) with maleic anhydride (2a) computed at M06-2X/6311++G(d,p) level of theory relative to $(1 a+2 a)$.

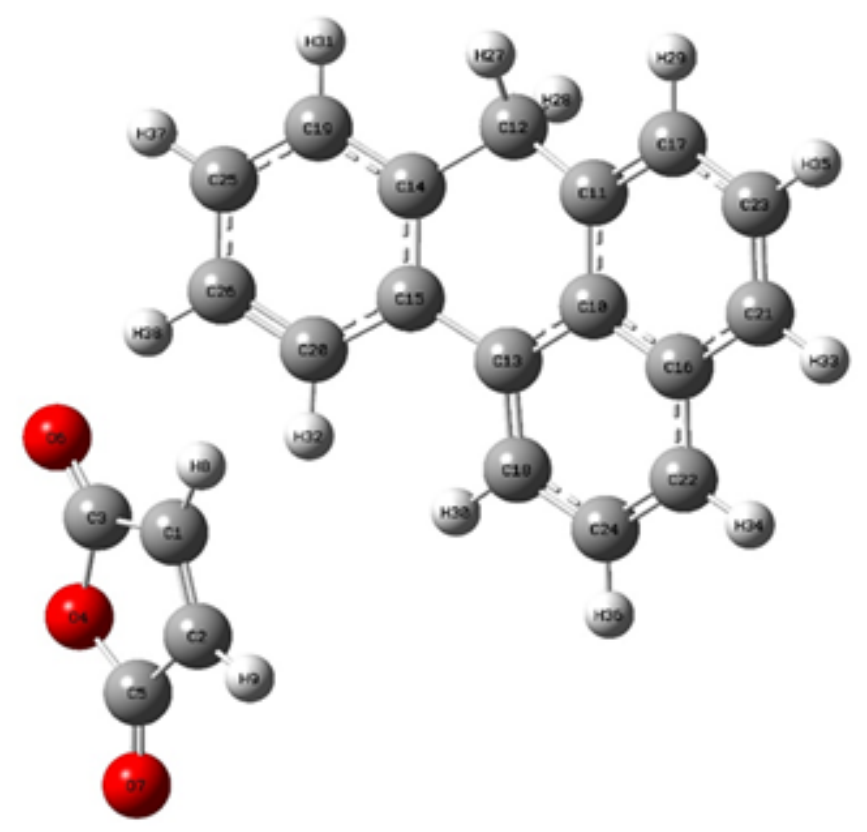

Figure 2 
Structure of reactants in scheme 1 ( $1 a$ and $2 a)$ with numbering and labels

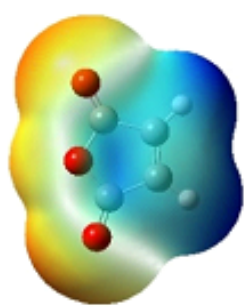

2a

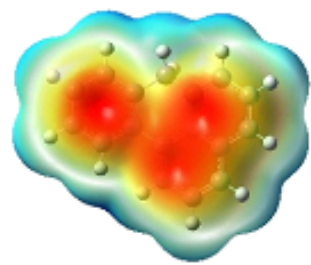

1a

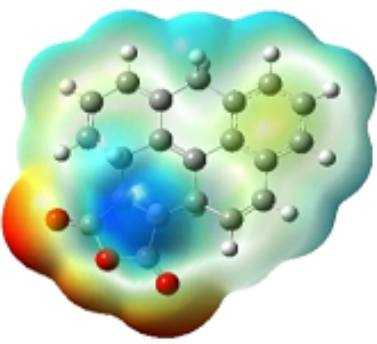

TS1a

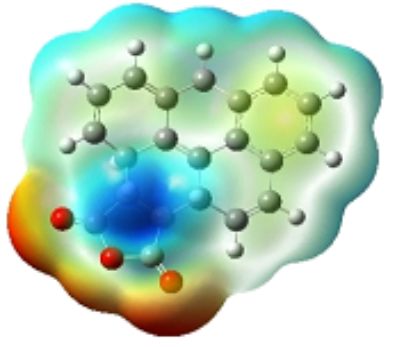

3a

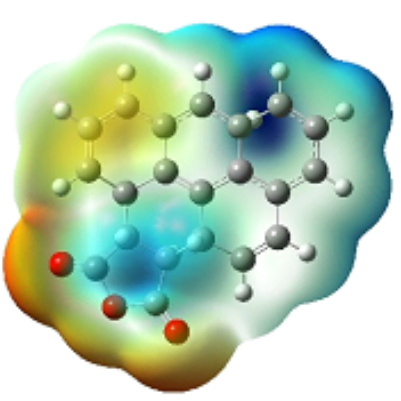

TS2a

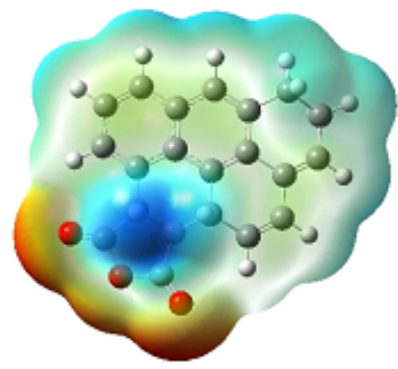

5a

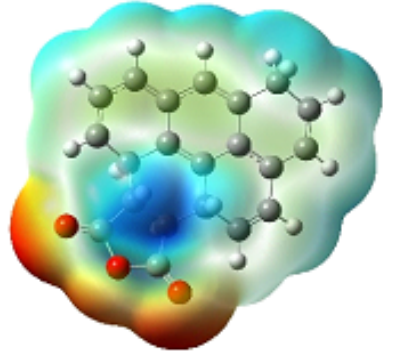

4a

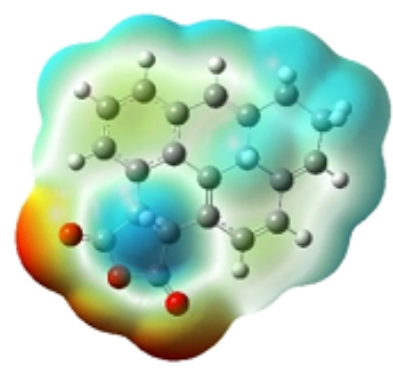

TS4a

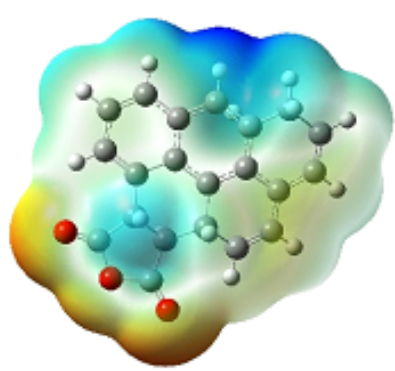

TS3a

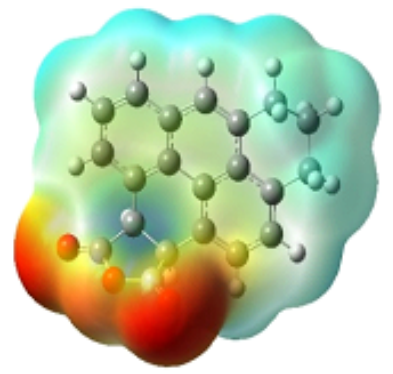

6a

Figure 3

MESP of all stationary points in scheme 1 at M06-2X/6311++G(d,p) 


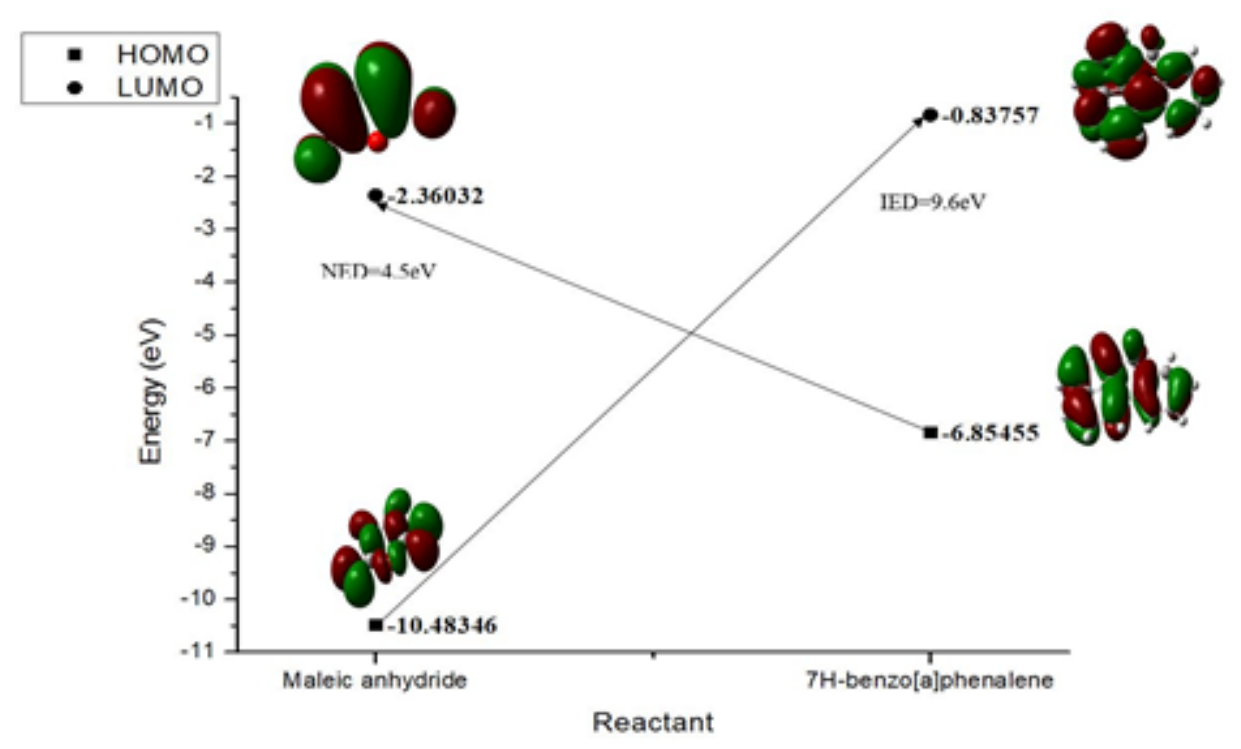

Figure 4

Possible interactions among FMOs of diene (1a) and dienophile (2a)

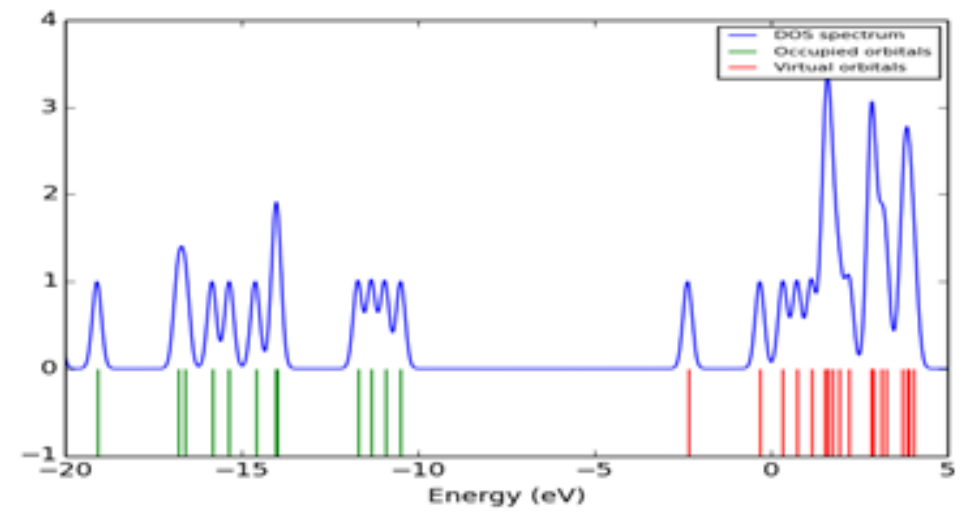

Figure 5

Energy of occupied and vritual orbitals for unsubstituted maleic anhydride (2a)

Figure 6

Energy of occupied and vritual orbitals for chloro maleic anhydride (2b)

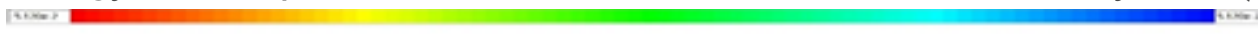

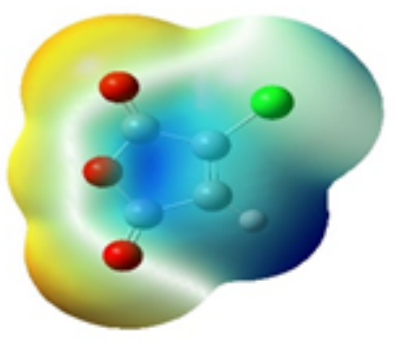


Figure 7

MESP of chloro maleic anhydride (2b) computed at M06-2x-6311++(d,p) level

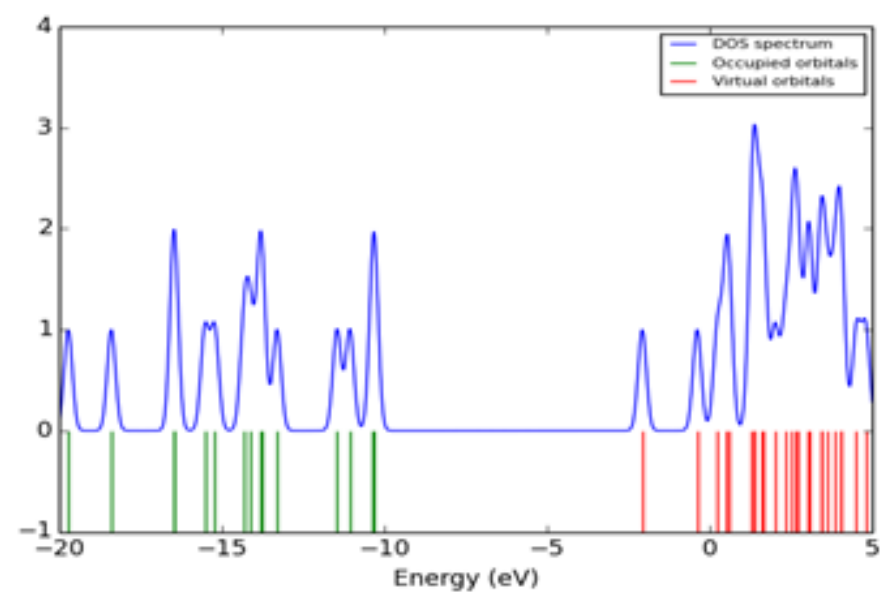

Figure 8

Energy of occupied and vritual orbitals for methyl substituted maleic anhydride (2c)

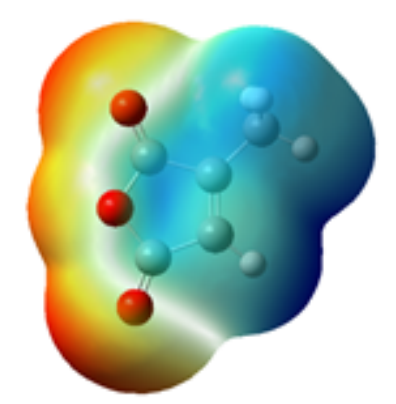

Figure 9

MESP of methyl maleic anhydride (2c) computed at M06-2x-6311++(d,p) level

\section{Supplementary Files}

This is a list of supplementary files associated with this preprint. Click to download.

- Scheme01.png

- Scheme02.png

- SupportingInformationUmmaturRehmanJMS.docx 